\title{
Research on the Constructive Methodology of Chinese Localization Curriculum Teaching Theory
}

\author{
Peipei Liu \\ Department of Students Service Neijiang Normal University, Neijiang, Sichuan, China, 641112 \\ smnod.u@163.com
}

Keywords: Localization; Teaching theory; Constructive methodology;

\begin{abstract}
This paper discusses the inheritance and innovation of traditional teaching theory from 3 aspects: the background of inheritance and innovation, the contents of inheritance and innovation and the method of inheritance and innovation. Then it talks about the generation of localization curriculum teaching theory in practice from the following 3 perspectives: the importance of teaching practice for curriculum teaching theory, the contribution and challenge of curriculum reform to the teaching theory and the practice generation method of localization course teaching theory. Finally, from the necessity, present situation and methods of the introduction and reference to discuss the accommodation and integration of curriculum teaching theory.
\end{abstract}

\section{Introduction}

This essay intends to study on how to construct the localization of curriculum teaching theory systematically and deeply based on methodology from the aspects of inheritance and innovation, theory and practice, introduction and reference, in order to promote the development of Chinese curriculum teaching theory. Therefore, study on the constructive methodology of localization curriculum teaching theory has great theoretical significance and practical value [1].

\section{Inheritance and Innovation}

The Background of Inheritance and Innovation. As a part of the traditional education theory, traditional course teaching theory has a long history with extensive and profound contents, and its unique spirit is a valuable education asset. In addition, it makes great contributions to the deepening of the curriculum reform of basic education and also the development of curriculum teaching theory, in order to adapt to the needs of education reform and the construction of socialist spiritual civilization [2].

Contents of Inheritance and Innovation. In the development process, Chinese education has formed and remained a lot of valuable course teaching traditions, including the "grown-up" teaching objective view, teaching principle view of "individualized instruction", teaching process view of "knowing and doing" and the concept of heuristic teaching method and comprehensive curriculum content view.

Any curriculum teaching theory cannot be completely out of the existing teaching ideology. These results are basis for the further development of curriculum teaching theory. However, with the change of the society and the continuous development of education, traditional teaching theory should combine with modern teaching practice to carry out theoretical exploration and promote the development, maturity and perfection of Chinese curriculum teaching theory with continuous innovation ${ }^{[3]}$. Modern teaching practice requires the innovation of traditional teaching objective view, including harmonious development of the teaching objective concept, the teaching principle view of application and development, the teaching process view of the combination of theory and practice, class-based teaching mode view and the education content view of the integration of humanity and science. 
The Methods of Inheritance and Innovation.(1) Penetration and integration

The localization of curriculum teaching theory is to form the curriculum theory with national characteristics under the standard of "modernization", so education localization is to take a creatively road of national education in accord with the connotation of "modernization". For this, we should strive to penetrate the new epoch content and style into the traditional curriculum teaching theory, pay attention to the integration of elements, make the inherited objects become a part of the modern teaching theory and avoid the curt docking between the essence of traditional curriculum teaching theory and modern curriculum teaching theory.

(2) Absorption and transformation

In the process of the localization of curriculum teaching theory, we should pay attention to implementing the comprehensive principle: treat traditions completely; consciously introduce foreign theories which are complementary with tradition, and combine them together; learn from the results of modern teaching theory and establish a new sense needed by the construction of modern curriculum teaching theory.

(3) Construction and transcendence

Focusing on construction, in fact, emphasizes that though the traditional curriculum teaching theory is important, at the same time, we should also pay attention to innovation. In the process of implementing this principle, we need to pay attention to the following aspects: select the essence the dross to allow the traditional theory to play its positive role; accept or reject, transformation and modernization of traditions should submit to the development needs of the new curriculum teaching theory.

\section{Theory and Practice}

Teaching Practice Is the Growth Soil of the Teaching Theory. Marxist epistemology holds that "theory comes from practice, while theory guides practice", suggesting that there exist a relation and unity between theory and practice. Similarly, between curriculum teaching theory and curriculum teaching practice, their also exist contact and unity.

(1) The concept of educational theory and educational practice

Educational theory is the systematic statement of educational problems formed by a series of educational concepts, judgments or propositions, with the help of a certain form of reasoning. Educational practice, as an important part of human social practice, is a series of individuals' or groups' social behaviors adopted by people for certain educational objectives with the use of some educational resources and conditions, and these behaviors are initiated on the basis of some certain ways and principles. It is the basic way for people actively to seek, create and enjoy the education in social life and to produce and provide education service or products ${ }^{[4]}$.

(2) Curriculum teaching practice is the source of curriculum teaching theory.

The curriculum teaching theory originates from the practice of curriculum teaching practice. The teaching practice is the original soil of curriculum teaching theory, and it is the original growth point, the new growth point and the dynamic source of the course teaching theory.

The Contribution and Challenge of Curriculum Reform to Curriculum Teaching Theory. The contribution of curriculum reform practice to the curriculum teaching theory mainly includes four aspects: the practice provides the material for the theory; the practice provides points for the theory; the practice provides examinations for the theory; the practice provides experiment $\mathrm{s}$ for the theory.

The implementation of the basic education curriculum reform has lasted for eight years, and achieved great success. But at the same time, in the implementation process, there have been some problems, which issues challenges on our current course teaching theory. The challenges are mainly from three aspects: the challenge of teachers' problems on curriculum and teaching subjects; the challenge of curriculum and teaching evaluation on quantitative evaluation; the challenge of curriculum management on three level curriculum management systems [5]. 
The Practical Construction Method of the Localization Curriculum Teaching Theory. As the implementation model of curriculum teaching theory, practice teaching not only shows that it is the basic premise and theoretical basis of curriculum teaching theory, and also indicates that it should comply with the theory instead of blindly following the theory. In the course teaching practice, in addition to the guidance of curriculum teaching theory, we should organize teaching in accordance with the goal of curriculum and instructional design, and also we can also utilize the collision of thought among students and teachers to generate new wisdom.

(1) Practice and analysis, to draw a conclusion from the practice.

(2) Experiment and practice, to prove whether the theory is correct or not.

(3) Revise and perfection, to make theory meet the needs of practice.

\section{Introduction and Reference}

The Necessity of Introduction and Reference. The So-called localization, neither means negating outstanding foreign teaching ideology completely, nor means the repeated criticism of their own teaching theory, but to extract the essence of traditional curriculum teaching theory, according to the actual situation of our country, in reference to the experience of other countries, to discover the common character, and also to find the fixed point, the starting point and the growth point to transform foreign experience, then to take appropriate development strategies to construct Chinese curriculum teaching theory with local characteristics. However, the so-called reference contains two meanings: one is the reference of successful methods from developed countries in the process of curriculum reform, while the second is the reference of reasonable components of the current curriculum mode in developed countries.

The necessity of introduction and reference includes the following aspects:

(1) It is the need of the development of modern curriculum teaching theory, and also the inevitable trend of the development of our curriculum teaching theory. What's more, it is also the results of the development of curriculum teaching theory.

(2) Owing to our country's present situation, in order to avoid detours and to make domestic curriculum teaching theory to integrate with international curriculum teaching theory as soon as possible, keeping the same level of development, we should critically identify and imitate foreign excellent theories on the basis of inheriting the traditional essence. Foreign excellent theories emphasize the integrality of intellectual development, individual differences, situationality and plasticity, which provides useful thoughts for the development and practice of China's current "research learning" curriculum.

The Analysis of the Current Situation of Introduction and Reference. Introduction Contents. In our country's current curriculum teaching theories, a large part of the teaching theories come from foreign educators. Since twentieth century, the localization of teaching theory can be divided into four stages.

(1) In the first twenty years of the last century, the basic assumption of the localization of curriculum theory in our country was to introduce the knowledge abroad which has universal significance and can reflect the basic law of curriculum into our country.

(2) From 1920s to liberation, during this period, our country's curriculum theory researchers introduced the curriculum theory directly from the experience of the west especially the United States. For research methodology, at that time, the research of the curriculum theory in our country was close to that of the West. In other words, China's curriculum theory was based on the mature curriculum theory of west countries, but also it was influenced by the political, economic and cultural situation of our country at that time.

(3) From liberation to the time before the reform and opening up, Kairov's teaching ideas were introduced to our country, which sets off a craze in our education circle to learn the former Soviet Union curriculum teaching theory. 
(4) Since the reform and opening up, a large number of foreign advanced theories have been introduced to our country, such as Tyler's curriculum development theory, Bruner's discovery teaching mode, Gardner's multiple intelligences theory and Doll's post-modern curriculum, which brings new vitality to Chinese curriculum teaching theory [6].

The Problems of Introduction. The input of foreign teaching theories has a history of 100 years. The centenary history is also our country's history of teaching theory construction. We have made a lot of achievements in the course of the history. Similarly, there are many problems worth noting: swallowing foreign teaching theories, blindly copying, imaging without foundation, emphasizing the introduction of science methods but ignoring humanistic methods.

Introduction and Reference Method. Presentation and Introduction. Presentation and introduction are the prerequisite to construct Chinese localization curriculum teaching theory. Only by comprehensively presenting and introducing foreign advanced teaching theory system, can we have a thorough understanding about these theories, so as to grasp the development trend of the curriculum teaching theory in the world, in order to promote the transformation and innovation of these excellent theories.

Therefore, we must comprehensively present and introduce Herbart's education thought, Dewey's pragmatism education theory, Kairov's former Soviet education thought, Taylor's theory of curriculum establishment and also Gardner's theory of multiple intelligences. Besides, we also need to understand about the development of phenomenology, hermeneutics, and modern philosophy in the curriculum teaching theory.

Comparison and Identification. For the introduction of foreign advanced curriculum teaching theories and thoughts, we can't simply transplant and copy them, as we also need to compare and identify these theories.

Firstly, we need to compare them, specifically analyzing the introduction contents, then to compare the essence, characteristics and the development law of these theories. Secondly, we need to identify them, which is a value judgment based on the comparison. Of course, every theory has its advantages, but if we consider whether this theory is compatible with the national curriculum teaching practice, then the theory has both advantages and disadvantages. Therefore, we must proceed from the actual situation of our country, foster strengths and circumvent weaknesses, learn from each other, to seek the best joint point.

Integration and Penetration. To construct Chinese localization teaching theory system, it is necessary to comprehensively introduce, compare and identify foreign advanced teaching theories, and we must also integrate these theories with Chinese domestic outstanding teaching theories, then to combine them with the current Chinese curriculum teaching practice, so as to fundamentally solve the problem.

For example, based on the "small steps" and immediate reinforcement principles proposed by American teaching experts Skinner about the procedural teaching, Lu Zhongheng Professor, from Psychology Institute of Chinese Academy of Sciences, applied the law of learning to carry out self-study coaching and teaching experiments for mathematics in junior middle school since 1963, and with continuous improvement, he formed a relatively complete and standardized self-study and tutorship teaching mode which is under the guidance and coach ship of teachers.

In short, to construct Chinese localization teaching theory system, we must first think about how Chinese curriculum teaching theory should establish their growth problems. Obviously, we should base on the Chinese curriculum teaching practice, while it not only means developing the useful and discarding the useless of Chinese traditional teaching theory and teaching discourse, but also means the real dialogue with other countries' teaching theory and practice, which is the best way to construct the localization of Chinese curriculum teaching theory. 


\section{Conclusion}

Construction of the localization of Chinese curriculum teaching theory is not to split the relation between traditional curriculum teaching theory and the modern one. What it emphasizes is the renewal and transformation of the essence of the traditional thought under the new historical and social conditions. Curriculum teaching theory should regard course teaching practice as the fixed point and growth point. At the same time, we also need to introduce and imitate foreign outstanding theories based on the inheritance of traditional essence, to enrich and strengthen our theoretical basis. All in all, the construction of the localization of Chinese curriculum teaching theory must innovate in inheritance, generate in practice and develop in introduction.

\section{References}

[1] Wenfeng W, Gao X, Journal of Multilingual and Multicultural Development, 29(5): 380-399, (2008)

[2] Gao X A, Liao Y, Li Y, Language Teaching, 47(01): 56-79, (2014)

[3] Autio T, International handbook of curriculum research: 17-31, (2013)

[4] He S, Zhou Y, Globalisation, Ideology and Politics of Education Reforms. Springer International Publishing: 73-85, (2015)

[5] Zou M, University of Warwick, (2014)

[6] Bai Y, Educational action research, 17(1): 143-154, (2009) 